\section{'Santonia Golden Lights': A Novel Intergeneric Hybrid of Sandersonia and Littonia (Colchicaceae)}

Ed R. Morgan, Garry K. Burge, and John F. Seelye

New Zealand Institute for Crop \& Food Research Limited, Private Bag 11 600, Palmerston North, New Zealand

\section{Andrew G.F. Warren}

Bloomz, Joyce Road, R.D. 3, Tauranga, New Zealand

David J. Brundell

Geophyte Exotics, P.O. Box 8, Waiuku, New Zealand

Additional index words. Sandersonia aurantiaca, Littonia modesta, flower breeding,

Colchicaceae

Sandersonia aurantiaca Hook. (Colchicaceae) is a relatively new and increasingly popular cut-flower crop. It is from South Africa, where it is found at altitudes of 600-2000 m and in summer rainfall areas (Brundell and Reyngoud, 1986). This species produces stems up to $1 \mathrm{~m}$ long, with up to 12 flowers on a stem (Brundell and Reyngoud, 1986). The flowers are $2-2.5 \mathrm{~cm}$ long and $1.3 \mathrm{~cm}$ in diameter. Flowers are golden-orange, lantern-shaped, and hang down from curved, wiry flower stalks originating at the leaf axils. The leaves are soft and narrow, ranging up to $10 \mathrm{~cm}$ long and 2 $\mathrm{cm}$ wide at their widest point before tapering to a thread-like tip. In mature plants, stems arise from the single growing point on the tip of each of the two lobes of the stoloniferous corm (Dahlgren et al., 1985). New Zealand growers refer to the stoloniferous corm as a tuber and to the lobes as legs. Growers break the tubers into two at the midpoint, where the legs are joined, and plant each leg separately to ensure that all growing points give rise to new plants. A bud is present at the tip of each leg, and gives rise to the new plant, which consists of a tuber comprising two legs joined to form a "vee" shape and a stem that is produced from the center of the joint. During the growing season the original leg completely withers and is lost.

In New Zealand, S. aurantiaca is grown for both cut flowers and as tubers for forcing. The export value of $S$. aurantiaca cut flowers in 2001 was just over NZ\$3M compared to NZ\$0.2M in 1990, with much of the New Zealand crop going to Japan. The 2001 export receipts for $S$. aurantiaca stems are down from the NZ\$5.6M exported in 1995. New Zealand growers and researchers have been successful in developing $S$. aurantiaca as a floricultural crop (Clark, 1994). Other countries, e.g., South Africa, are now beginning to produce S. aurantiaca. For New Zealand to maintain its market share, new cultivars must be developed and introduced to the industry. Sandersonia aurantiaca is a monospecific genus in which

Received for publication 29 Jan. 2002. Accepted for publication 2 July 2002. little variation has been observed among seedpropagated plants. Therefore, hybridization programs must include species from related genera. Sandersonia aurantiaca is a member of the Colchicaceae (Dahlgren et al., 1985) and any breeding programs must involve other genera from this family.

Littonia modesta Hook. (Colchicaceae), also of South African origin, is sometimes used in horticulture as a cut flower or as an ornamental plant. It is a relative of $S$. aurantiaca that climbs using tendrilous leaf tips to cling arrangement of leaves on the stem. to supporting structures. Stem length depends on tuber size, but plants can reach in excess of $2 \mathrm{~m}$. Flowers are golden-orange and bell shaped with six separate tepals. The flowers are borne on pedicels that usually originate in leaf axils. Leaves are hard-textured and up to $20 \mathrm{~cm}$ long and $3 \mathrm{~cm}$ wide, terminating in a tendril. Shoots grow from the tips of forkshaped tubers similar to $S$. aurantiaca.

'Santonia Golden Lights' (S. aurantiaca $x$ L. modesta) was released by Sanza in New Zealand in 1998. Plant variety rights have been obtained for this cultivar in New Zealand.

\section{Origin}

'Santonia Golden Lights' is a S. aurantiaca $\mathrm{x}$ L. modesta $\mathrm{F} 1$ hybrid with $S$. aurantiaca as the female parent. The hybrid was produced by in ovulo embryo culture (Morgan et al., 2001).

\section{Description}

Plants have leaf and flower morphologies intermediate between the two parent species. Leaves of 'Santonia Golden Lights' terminate with tendrils whereas those of S. aurantiaca do not. The flowers of 'Santonia Golden Lights' have six tepals that are fused for half of their length. In $S$. aurantiaca the tepals are fused for almost their entire length and in L. modesta the tepals are barely fused. The flower color of 'Santonia Golden Lights' and the two parents is the same (RHS colour chart 23A), although

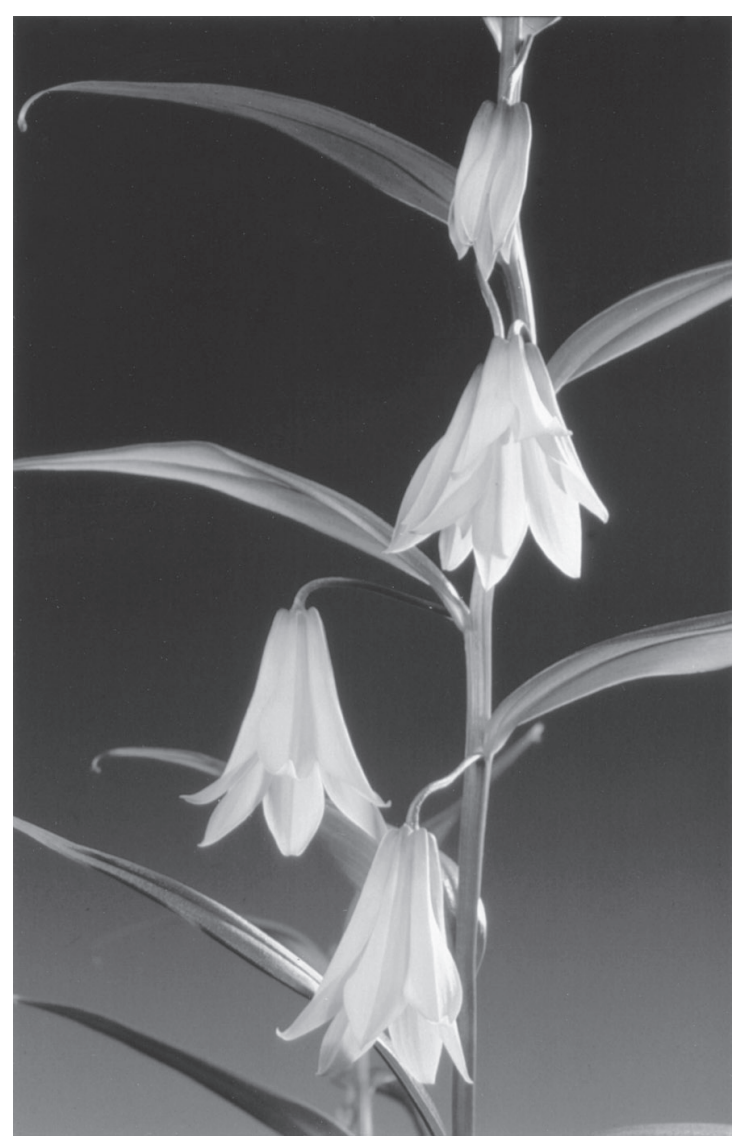

Fig. 1. A flowering stem of 'Santonia Golden Lights', showing the morphology of the flowers and the 
there is often some reddening of flowers when grown in cooler outdoor environments at a range of locations in New Zealand. Up to 30 flowers can be produced on a single stem. Flower form and the arrangement of leaves on a stem are shown in Fig. 1.

Stem length is dependent on both tuber size and the growing environment. Under ambient outdoor growing environments in New Zealand stem length is about $80 \mathrm{~cm}$, but under warmer (minimum $18^{\circ} \mathrm{C}$ ) greenhouse conditions stem length can be over $2 \mathrm{~m}$.

\section{Characteristics and use}

Most aspects of 'Santonia Golden Lights' tuber and flower production are similar to those of $S$. aurantiaca. However, there are differences, some of which are crucial for the production of quality cut stems or tubers. 'Santonia Golden Lights' tubers are much larger than those of $S$. aurantiaca (some $>100 \mathrm{~g}$ ) and the tubers often have three or more legs, making multiplication by tuber division more rapid. Further, stem length and strength are greatly influenced by the growing environment; only under cooler, outdoor conditions have stems been produced with the length, strength, and attractive appearance that makes them suitable for use as cut stems.

'Santonia Golden Lights' can be grown as a potted plant or cut flower. Stem length and time to flowering are influenced by a number of factors, including tuber size, growing environment, and duration of tuber storage (unpublished data). In Oct. 1995 (New Zealand spring), tubers were planted into a screen house (10\% shading) at ambient temperatures (daily mean maximum temperature $20^{\circ} \mathrm{C}$, daily mean minimum temperature $8.5^{\circ} \mathrm{C}$ ) and into a heated glasshouse (minimum $18{ }^{\circ} \mathrm{C}$ ). Flowering occurred 3 weeks earlier in the warmer environment, commencing $8 \mathrm{Dec}$. in the glasshouse and $28 \mathrm{Dec}$. in the screen house. Plants grown in the glasshouse produced longer stems than those in the screen house. Stems can be harvested at a relatively early stage (two or three flowers orange) to give a vase life in excess of $10 \mathrm{~d}$ in water (Eason et al., 2001).

Individual tubers of 'Santonia Golden Lights' typically produce two or three legs, each of which has a single growing point at its tip. However, leg numbers can vary depending on growing conditions, and up to 20 legs have been seen on a single tuber. If tubers are large enough they can be divided at planting to ensure that all tuber tips sprout and produce a flowering stem. One difficulty in producing flowering size tubers can be the high proportion of daughter tubers with secondary tubers. When planting $S$. aurantiaca, the two legs of the tuber are separated to ensure that the growing point at the tip of each leg will produce a flowering stem. Shortly after the stem begins growing, a new tuber (daughter) is initiated at the lowest node on the stem; this daughter tuber is the propagule that survives to the following season. If grown incorrectly, secondary tubers can be produced at the tips of the two legs of the daughter tuber in the same growing season. Secondary tubers are a problem as they are small and easily break off the daughter tuber, leaving the larger daughter tuber without growing points. The frequency of secondary tuber formation is increased by high nutrition levels and less dense tuber spacings in a manner analogous to $S$. aurantiaca (Clark and Burge, 1997a, 1997b, 1999).

Tubers are dormant when the stem senesces. Tuber dormancy is broken with storage at 3-10 ${ }^{\circ} \mathrm{C}$ for 6 weeks as for $S$. aurantiaca (Clark, 1994). Tubers stored for longer than 15 weeks must be stored at low $\left(3{ }^{\circ} \mathrm{C}\right)$ temperatures to prevent sprouting. There is some tuber weight loss (up to $15 \%$ ) when tubers are stored dry but the weight loss is reduced when tubers are stored in moist sawdust or newspaper. Storage rots may occur but can be controlled using fungicide dips, as reported for S. aurantiaca (Clark, 1994).

\section{Availability}

'Santonia Golden Lights' is a sterile hybrid that can only be propagated vegetatively. Plant material is available from Sanza, c/o Bloomz, Joyce Road, R.D. 3, Tauranga, New Zealand. This cultivar has been granted Plant Variety Rights in New Zealand. Inquiries as to availability of plant material for evaluation in other countries should be made to the above address or to http://www.bloomz.co.nz.

\section{Literature Cited}

Brundell, D.J. and J.L. Reyngoud. 1986. Observations on the development and culture of Sandersonia. Acta Hort. 177:439-447.

Clark, G.E. 1994. Sandersonia. Crop \& Food Research Broadsheet. No. 46. New Zealand Inst. for Crop \& Food Res. Ltd., Christchurch, New Zealand.

Clark, G.E. and G.K. Burge. 1997a. Effects of growing environments, planting date and stem treatments on Sandersonia tuber weight and secondary tuber development. N.Z. J. Crop and Hort. Sci. 25:67-72.

Clark, G.E. and G.K. Burge. 1997b. Effects of planting density, stem pruning treatments and shade on secondary tuber development in Sandersonia aurantiaca. N.Z. J. Crop and Hort. Sci. 25:73-78.

Clark, G.E. and G.K. Burge. 1999. Effects of nitrogen nutrition on Sandersonia cut flower and tuber production in soil-less media. N.Z. J. Crop and Hort. Sci. 27:145-152.

Dahlgren, R.M.T., H.T. Clifford, and P.F. Yeo. 1985. The families of Monocotyledons: Structure, evolution and taxonomy. Springer-Verlag Publ., Berlin, Heidelberg, New York, Tokyo.

Eason, J.R., E.R. Morgan, A.C. Mullan, and G.K. Burge. 2001. Postharvest characteristics of Santonia 'Golden Lights' a new hybrid cut flower from Sandersonia aurantiaca $\times$ Littoniamodesta. Postharvest Biol. and Tech. 22:93-97.

Morgan, E.R., G.K. Burge, J.F. Seelye, M.E. Hopping, J.E. Grant, A.G.F. Warren, and D.J. Brundell. 2001. Wide crosses in the Colchicaceae: Sandersonia aurantiaca $\times$ Littonia modesta. Euphytica 121:343-348. 